\title{
Prison brain? Executive dysfunction in prisoners
}

\author{
Jesse Meijers $^{1 *}$, Joke M. Harte ${ }^{2,3}$, Frank A. Jonker ${ }^{1}$ and Gerben Meynen ${ }^{4,5}$ \\ ${ }^{1}$ Department of Clinical Neuropsychology, VU University Amsterdam, Amsterdam, Netherlands \\ ${ }^{2}$ Department of Criminal Law and Criminology, VU University Amsterdam, Amsterdam, Netherlands \\ ${ }^{3}$ Netherlands Institute for the Study of Crime and Law Enforcement. Amsterdam, Netherlands \\ ${ }^{4}$ Faculty of Philosophy, VU University Amsterdam, Amsterdam, Netherlands \\ ${ }^{5}$ Department of Criminal Law, Tilburg Law School, Tilburg University, Tilburg, Netherlands
}

\section{Edited by:}

Bernhard Hommel, Leiden

University, Netherlands

Reviewed by:

Thomas Kleinsorge, Leibniz Research Centre for Working

Environment and Human Factors,

Germany

Joseph Hubertus Roald Maes,

Radboud University, Netherlands

*Correspondence:

Jesse Meijers, Department of

Clinical Neuropsychology, Faculty of

Psychology and Education, VU

University Amsterdam, Room 1F-66,

Van der Boechorststraat 1,

1081 BT Amsterdam, Netherlands

e-mail: j.meijers@vu.nl
A better understanding of the functioning of the brain, particularly executive functions, of the prison population could aid in reducing crime rates through the reduction of recidivism rates. Indeed, reoffending appears to be related to executive dysfunction and it is known that executive functions are crucial for self-regulation. In the current paper, studies to executive functions in regular adult prisoners compared to non-offender controls were reviewed. Seven studies were found. Specific executive functions were found to be impaired in the general prison population, i.e., attention and set-shifting, as well as in separate subgroups of violent (i.e., set-shifting and working memory) and non-violent offenders (i.e., inhibition, working memory and problem solving). We conclude that the limited number of studies is remarkable, considering the high impact of this population on society and elaborate on the implications of these specific impairments that were found. Further empirical research is suggested, measuring executive functioning within subjects over time for a group of detainees as well as a control group.

Keywords: executive functions, impoverished environment, offenders, prison, recidivism, mini-review

\section{INTRODUCTION}

More than 11 million people worldwide are in some form detained (Walmsley, 2013), most of them as pre-trial detainees (remand prisoners) or sentenced prisoners. In all continents, the prison population continues to grow (Walmsley, 2013). As the prison population grows, and since crime carries a great (e.g., social and economical) burden (McCollister et al., 2010), reducing recidivism is of great interest to society.

Recidivism rates of prisoners in various countries range between 35 and 67 percent (Langan and Levin, 2002; Spicer et al., 2004; Federal Ministry of the Interior, 2006; Wartna and Nijssen, 2006; Wartna et al., 2012). Several risk factors for recidivism have been identified, such as various demographic risk factors as age and sex (Piquero et al., 2013), unemployment (Verbruggen et al., 2012), and substance abuse (Håkansson and Berglund, 2012). Another risk factor for recidivism is a decline in general self-regulation (Mann et al., 2010) and executive dysfunction (Hancock et al., 2010; Langevin and Curnoe, 2011; Ross and Hoaken, 2011). Executive functions are higher order cognitive functions including planning, working memory, taking initiatives, set-shifting, attention, and impulse control (Jurado and Rosselli, 2007; Diamond, 2013). These functions are crucial for self-regulation (Hofmann et al., 2012). Upon re-entry in society, prisoners face many challenges that place a demand on executive functions. For example, one has to take initiatives, has to be able to plan and think things over, e.g., in order to find housing and employment, both being risk factors for reoffending (Luther et al., 2011). Consequently, executive dysfunction may cause an increase in reoffending, through failure in self-regulation.
In an extensive meta-analysis on the relationship between antisocial behavior and executive functions (Ogilvie et al., 2011), a robust positive association was found between criminality (i.e., people who have committed a crime at some point in their lives) and executive function deficits, with a moderate to large effect size $(d=0.6)$. This relationship between antisocial behavior and executive function deficits has also been clearly shown by other studies, like Morgan and Lilienfeld (2000). However, in these studies heterogenic populations including ex-detainees and patients in forensic hospitals were examined. Even though this may provide useful information for prison policy and (mental) health care, executive (dys)functions in regular (e.g., nonhospitalized) adult prisoners have not been reviewed separately. The goal of this systematic review is to provide an overview of studies addressing executive functions in the regular prisoner population.

\section{METHODS}

\section{SEARCH}

The aim of our search was to identify studies examining executive functions in regular prison populations, in comparison to nonoffender controls. We performed an extensive search in PubMed, Embase, Web of Science and PsycINFO, using a combination of large series of relevant keywords and e.g., MeSH terms (PubMed) or Emtree terms (Embase), such as detained, detention, offenders, executive function and neuropsychological. All prison-related terms were contained within brackets, separated by the "OR" boolean operator, as were all executive function-related terms. The prison-related terms and executive function-related terms 
were then connected in the final search, as follows: "(prisonrelated terms) AND (executive function related terms)." The complete search in PubMed, containing all used terms, is provided in Appendix 1 in Supplementary Material. Similar searches were conducted in Embase, Web of Science and PsycINFO. Other relevant articles were found by manually searching bibliographies of already gathered studies.

The combined searches, conducted in February 2013, delivered 1236 results. Two independent reviewers read all the abstracts, which resulted in 190 articles to be read as full text articles. Out of these 190 full text articles, the two independent reviewers found 7 articles meeting all inclusion criteria. An updated search in July 2014 did not produce any additional articles meeting the inclusion criteria.

\section{INCLUSION CRITERIA}

Only studies that contained at least one group of adult prisoners and one group of controls (i.e., persons without a history of criminal behavior), which were compared in at least one test of executive functioning, were included. Tests of executive functioning were defined as tests that measured one or more of the following functions: planning, working memory, attention, set-shifting, inhibition/impulse control or problem-solving (Diamond, 2013). Studies were only considered for inclusion if published in the English language. A total of 7 studies fulfilled these criteria and were included in this review. Table 1 provides an overview of the included studies characteristics, like sample size, neuropsychological tasks used and effect sizes.

\section{EFFECT SIZES}

Effect sizes (Cohen's D) were manually calculated by the authors where possible, and were classified as small $(d \geq 0.2)$, moderate $(d \geq 0.5)$ or large $(d \geq 0.8)$ (Cohen, 1992). For studies with insufficient data to calculate Cohen's D, effect sizes as reported in the studies were used if available.

\section{RESULTS}

\section{SET-SHIFTING (3 STUDIES)}

Compared to controls, offenders performed significantly worse on set-shifting (Letter Fluency; Baker and Ireland, 2007). Violent offenders in this group performed significantly worse than controls $(d=1.09)$, while the non-violent offenders did not differ significantly, although a moderate effect size was found $(d=0.58)$. Recent findings suggest that certain tasks, e.g., letter fluency, differentiate better between offenders and controls than others (Schiffer and Vonlaufen, 2011). More specifically, moderate effect sizes, implying worse performance of the offenders, were found $(d=0.52-0.76)$ on various other measures of set-shifting (Category Fluency, Wisconsin Card Sorting Test, Trail Making Test), although the differences were not statistically significant. In a study comparing offenders detained for impulsive drug-related crimes with a control group (Kavanagh et al., 2010), no significant effects were found for both Letter Fluency and Word Fluency. In sum, based on the moderate to large effect sizes, it appears that set-shifting may be impaired in both violent and non-violent offenders.

Table 1 | Effect Sizes of Studies with Violent Offenders.

\begin{tabular}{|c|c|c|c|c|}
\hline Authors (Year) & Offender sample & Control sample & Functions (Tasks) & $\begin{array}{l}\text { Effect Size } \\
\text { (Cohen's D) }\end{array}$ \\
\hline Baker and Ireland, 2007 & $\begin{array}{l}\text { 60, of which: } \\
42 \text { Violent } \\
18 \text { Non-violent }\end{array}$ & 32 University students & $\begin{array}{l}\text { Set-shifting } \\
\text { (Benton Word Fluency) }\end{array}$ & $\begin{array}{l}1.09 \\
0.58\end{array}$ \\
\hline $\begin{array}{l}\text { Greenfield and Valliant, } \\
2007\end{array}$ & $\begin{array}{l}\text { 39, of which: } \\
20 \text { Violent } \\
19 \text { Non-violent }\end{array}$ & 20 University students & $\begin{array}{l}\text { Planning } \\
\text { (Porteus Maze) }\end{array}$ & $\begin{array}{l}0.41 \\
0.06\end{array}$ \\
\hline Hoaken et al., 2007 & $\begin{array}{l}\text { 40, of which: } \\
20 \text { Violent } \\
20 \text { Non-violent }\end{array}$ & $\begin{array}{l}20 \text { Respondents to } \\
\text { advertising from university } \\
\text { and community }\end{array}$ & $\begin{array}{l}\text { Working memory } \\
\text { (CSOWM, ASOWM) }\end{array}$ & $\begin{array}{l}\text { N/A } \\
\text { N/A }\end{array}$ \\
\hline Kavanagh et al., 2010 & 29 General population & $\begin{array}{l}58 \text { From normative sample in } \\
\text { Brain Resource International } \\
\text { Database }\end{array}$ & $\begin{array}{l}\text { Attention, Set-shifting, Planning, Working } \\
\text { Memory } \\
\text { (CPT, Letter Fluency, Word Fluency, Maze } \\
\text { Reverse Digit Span) }\end{array}$ & $\mathrm{N} / \mathrm{A}$ \\
\hline Munro et al., 2007 & 15 Violent & 15 Facility Staff & $\begin{array}{l}\text { Inhibition } \\
\text { (Go/No-Go Task) }\end{array}$ & 0.8 \\
\hline $\begin{array}{l}\text { Santos Barbosa and Coelho } \\
\text { Monteiro, } 2008\end{array}$ & 30 Non-violent recidivists & 30 Facility Staff & $\begin{array}{l}\text { Inhibition, Planning, Problem Solving } \\
\text { (BADS) }\end{array}$ & $0.85-1.66$ \\
\hline Schiffer and Vonlaufen, 2011 & 16 violent & $\begin{array}{l}17 \text { respondents to advertising } \\
\text { from community }\end{array}$ & $\begin{array}{l}\text { Set-shifting, Planning, Inhibition } \\
\text { (WCST, TMT, Word Fluency, Go/No-Go, TOL) }\end{array}$ & $\begin{array}{l}0.52-0.77 \\
\text { (Set-Shifting) } \\
0.15 \text { (Planning) } \\
0.03 \text { (Inhibition) }\end{array}$ \\
\hline
\end{tabular}

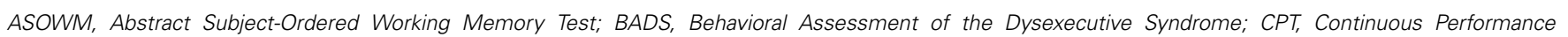

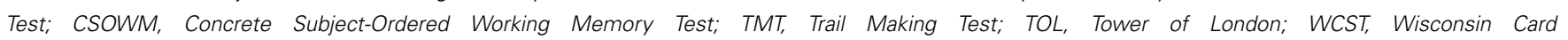
Sorting Test. 


\section{PLANNING (4 STUDIES)}

As with set-shifting, different planning tasks yield inconsistent results. Non-violent offenders performed significantly worse than controls on several planning subtasks of the Behavioral Assessment of the Dysexecutive Syndrome (BADS; Santos Barbosa and Coelho Monteiro, 2008), with large effect sizes ( $d=$ 1.00-1.66). However, using the Porteus Maze Test, another planning task, non-violent offenders did not show significantly worse performance than controls (Greenfield and Valliant, 2007), with a negligible effect size $(d<0.1)$. In the same study, a moderate effect size $(d=0.41)$, implying worse performance, was found for violent offenders, although this difference with controls was also not statistically significant. Similarly, in another study using a similar type of Maze test (Kavanagh et al., 2010), no significant differences were found between offenders detained for impulsive drug related crime and controls. A lack of significance was also observed after administering the Tower of London to violent offenders (Schiffer and Vonlaufen, 2011); the effect size $(d<0.2)$ between violent offenders and controls was small.

These findings suggest that only a planning task with an ecological value (BADS; Norris and Tate, 2000), differentiates between offenders and controls. In other words, the BADS may be a better predictor of actual functioning than the other, classic neuropsychological tasks. Inconsistent findings may furthermore be caused by differences between the study populations regarding the rates of recidivism, as more (pronounced) dysfunction could be expected in recidivists (Hancock et al., 2010; Langevin and Curnoe, 2011).

\section{WORKING MEMORY (2 STUDIES)}

Three tests, primarily appealing to working memory, were administered to violent and non-violent offenders and controls (Hoaken et al., 2007). Of note is that in this study a single unitary executive function variable was created of these three measures. Both violent and non-violent offenders showed significantly worse working memory performance, compared to the control group. In a study comparing offenders detained for impulsive drugrelated crime with controls, no difference was found in the Backward Digit Span task (Kavanagh et al., 2010). It should be noted, however, that the Backward Digit Span task is a much less comprehensive task than those used in the first study.

\section{INHIBITION (3 STUDIES)}

Three studies assessed inhibition in offenders. In two of these studies inhibition was assessed using a Go/No-Go task in violent offenders (Munro et al., 2007; Schiffer and Vonlaufen, 2011). The first study (Schiffer and Vonlaufen, 2011) found no difference in performance between the offenders and controls $(d<$ 0.1 ). Of note is that the authors reported that their sample consisted of prisoners who mainly had a history of instrumental, rather than impulsive violence, already indicating a lower risk of reduced impulse control. In contrast, the latter study (Munro et al., 2007) did find significantly worse performance of the violent offenders $(d=0.8)$. As both studies had similar sample sizes, similar intelligence values in both the offender and control groups, and controlled for the influence of age and years of education, the inconsistent findings are most likely due to the non-impulsive nature of the participants of the first study (Schiffer and Vonlaufen, 2011).

In the study of Santos Barbosa and Coelho Monteiro (2008), inhibition (using a subtask of the BADS) was significantly worse in non-violent offenders, compared to 30 controls, with a large effect size ( $d=0.85$; Santos Barbosa and Coelho Monteiro, 2008). As mentioned before, the sample in this study mainly consisted of recidivists, and it should be noted that recidivism appears to be related to worse executive functioning (Hancock et al., 2010; Langevin and Curnoe, 2011).

In sum, the findings suggest impaired inhibition in both violent and non-violent offenders, with the exception of those prisoners characterized by a history of premeditated, non-impulsive violent crimes.

\section{ATTENTION (1 STUDY)}

Only one study assessed attention in offenders (Kavanagh et al., 2010). The offenders, a random general sample of offenders, performed significantly worse than controls on the attention task, as the authors report a semipartial correlation of 0.38 .

\section{PROBLEM SOLVING (1 STUDY)}

Using the Action Program subtask of the BADS, no significant difference in problem solving outcome was found in 30 non-violent offenders, compared to 30 controls (Santos Barbosa and Coelho Monteiro, 2008). However, the offenders did need significantly more time to achieve the same outcome (i.e., solve the problem), with a moderate to large effect size $(d=0.77)$.

\section{DISCUSSION}

In view of the millions of prisoners worldwide, and the high impact of this population on society, it is striking that only 7 studies were found that examined the executive functions of the general prison population. Furthermore, most studies assessed only some specific executive functions instead of a wide range, and sample sizes were small. Consequently, the results of these studies should be considered with caution. Nevertheless, the findings suggest the existence of various executive function deficits in regular prisoners.

Distinct executive function deficits were found in attention, set-shifting, working memory, problem-solving and inhibition, of which the possible consequences of the consistently found executive dysfunctions will be addressed.

One executive function that was found impaired is inhibition. Inhibition comprises deliberately suppressing ones dominant responses or impulses (Miyake et al., 2000), e.g., in order to think before acting aggressively (Brower and Price, 2001). Prisoners may have difficulties suppressing harmful impulses, such as aggressive impulses.

Set-shifting comprises the ability to change perspectives (Diamond, 2013), for example to think of new solutions for persisting problems, or switch from dysfunctional behavior to more functional behavior. The impaired set-shifting found in prisoners therefore suggests that they may experience increased difficulties to desist from old dysfunctional behavior and to think of other, more effective solutions to their problems.

Working memory provides the ability to actively hold information in mind, and work with that information, for example to 
keep a certain goal in mind and integrate new relevant information, while discerning irrelevant information (Diamond, 2013). The impaired working memory found in both groups may contribute to a decline in the ability to work toward aforementioned, relatively complex goals, such as finding housing and employment.

Problem solving was found impaired in non-violent offenders. This finding indicates difficulties with solving problems that will arise upon re-entry in society. No studies assessed problemsolving in violent offenders.

As postulated by Miyake et al. (2000), "executive functions are separable but related functions that share some underlying commonality." In this review, the specific (separable) executive function deficits that were found, are all related to goal-directed behavior and may thus all result in similar problems. We therefore hypothesize that executive dysfunction in regular prisoners has important implications for future reoffending. Further research on this important topic is clearly required.

Out of various treatment strategies, e.g., sanctions and supervision, rehabilitation treatment and cognitive behavior interventions, cognitive behavior interventions focusing on improving specific cognitive skills (e.g., inhibition) were found to be the most effective in decreasing recidivism (Lipsey and Cullen, 2007). However, the results are still unsatisfactory (Ross and Hoaken, 2010) and broad implementation of these interventions is lacking (Lipsey and Cullen, 2007). One might wonder what the effect of comprehensive enrichment of the prison environment itself would lead to, as opposed to occasional treatment. Executive functions have been shown to be positively related to environmental enrichment, e.g., increased physical activity improves executive functions in all age groups (Kramer et al., 1999; Colcombe and Kramer, 2003; Hillman et al., 2008), in particular in those who are sedentary (Scherder et al., 2013). Besides sensorimotor stimuli (physical activity), such comprehensive enrichment of the environment could also comprise enhanced cognitive (e.g., education, occupation) and social challenges (Petrosini et al., 2009). In addition, executive functions of prisoners could be individually assessed, allowing prisons to offer more specific training for prisoners with specific executive function impairments (Ross and Hoaken, 2010).

Prison, however, is currently a clear example of an impoverished and sedentary environment. Prison life is characterized by a lack of demand on self-regulating functions, e.g., prisoners are barely confronted with choices to make and have little control over their daily activities (Woodall et al., 2013). Moreover, prisoners may experience resistance from an inflexible prison system, for example when they take the initiative to seek specific health care treatment (Stoller, 2003). In addition, prisoners spend most of their time with passive leisure activities, such as watching television (Elger, 2009). Studies in various countries show that prison is characterized by physical inactivity (Young et al., 2005; Ireland and Culpin, 2006; Cashin et al., 2008; Plugge et al., 2009). For example, prisoners sit or lie on their beds for a striking $9.36 \mathrm{~h}$ per day on average, besides the hours spend sleeping (Ireland and Culpin, 2006). As we know from animal studies, an impoverished environment has a negative effect on the prefrontal cortex (Winterfeld et al., 1998; Melendez et al., 2004; Bagorda et al., 2006;
Witte et al., 2007), a brain region crucial for executive functions (Jurado and Rosselli, 2007). In the elderly, impoverishment in the form of physical inactivity is related to decreased self-regulation, i.e., increased agitation (Scherder et al., 2010). Thus, the current impoverished prison environment may diminish executive functions and, indirectly, lead to increased recidivism rates. At the same time, an enriched environment may be beneficial to these functions and, in the end, enable successful re-entry in society.

This review shows an emerging field of research that has yet to develop, since large studies with matched healthy control groups are lacking. This development may be challenged by the unique obstacles researchers encounter when conducting research in the prison environment (Vanderhoff et al., 2011), for example logistical difficulties (e.g., lack of testing space, insufficient testing time) or safety issues (e.g., lack of available security staff, obligatory handcuffs during testing). However, as crime carries a considerable (financial) burden to society (McCollister et al., 2010), it is a field with great societal relevance.

In conclusion, the reviewed studies suggest various executive dysfunctions in regular prisoners. This may be due to the higher chance of impairment in antisocial individuals (Ogilvie et al., 2011), deterioration of executive functions caused by the prison environment, or a combination of both. Either way, we hypothesize that the impoverished prison environment, depriving its population of many normal stimuli, may lead to (further) deterioration of executive functions. Within the view that executive functions are crucial for successful re-entry in society, it is imperative that the possible influence of the prison environment is further researched. For future studies to the influence of the prison environment on executive functions, we advise recruiting new detainees for a baseline measurement, and reassessing these new detainees within a certain timeframe, e.g., 3 or 6 months. Combined with a non-offender control group at baseline, it is possible to distinguish dysfunctions that were already present upon imprisonment (which may also have contributed to the imprisonment itself) and dysfunctions caused or worsened by the prison environment.

\section{SUPPLEMENTARY MATERIAL}

The Supplementary Material for this article can be found online at: http://www.frontiersin.org/journal/10.3389/fpsyg. 2015.00043/abstract

\section{REFERENCES}

Bagorda, F., Teuchert-Noodt, G., and Lehmann, K. (2006). Isolation rearing or methamphetamine traumatisation induce a "dysconnection" of prefrontal efferents in gerbils: implications for schizophrenia. J. Neural Transmission 113, 365-379. doi: 10.1007/s00702-005-0324-2

Baker, S. F., and Ireland, J. L. (2007). The link between dyslexic traits, executive functioning, impulsivity and social self-esteem among an offender and non-offender sample. Int. J. Law Psychiatry 30, 492-503. doi: 10.1016/j.ijlp.2007.09.010

Brower, M. C., and Price, B. H. (2001). Neuropsychiatry of frontal lobe dysfunction in violent and criminal behaviour: a critical review. J. Neurol. Neurosurg. Psychiatr. 71, 720-726. doi: 10.1136/jnnp.71.6.720

Cashin, A., Potter, E., and Butler, T. (2008). The relationship between exercise and hopelessness in prison. J. Psychiatr. Ment. Health Nurs. 15, 66-71. doi: 10.1111/j.1365-2850.2007.01207.x

Cohen, J. (1992). A power primer. Psychol. Bull. 112, 155-159. doi: 10.1037/00332909.112.1.155 
Colcombe, S., and Kramer, A. F. (2003). Fitness effects on the cognitive function of older adults: a meta-analytic study. Psychol. Sci. 14, 125-130. doi: 10.1111/14679280.t01-1-01430

Diamond, A. (2013). Executive functions. Annu. Rev. Psychol. 64, 135-168. doi: 10.1146/annurev-psych-113011-143750

Elger, B. S. (2009). Prison life: television, sports, work, stress and insomnia in a remand prison. Int. J. Law Psychiatry 32, 74-83. doi: 10.1016/j.ijlp.2009. 01.001

Federal Ministry of the Interior. (2006). Second Periodical Report on Crime and Crime Control in Germany. Available online at: http://www.uni-konstanz.de/rtf/ ki/SecondPeriodicalReporton Crimeanden.pdf [Accessed July 2014].

Greenfield, R., and Valliant, P. M. (2007). Moral reasoning, executive function, and personality in violent and nonviolent adult offenders. Psychol. Rep. 101, 323-333. doi: 10.2466/pr0.101.1.323-333

Håkansson, A., and Berglund, M. (2012). Risk factors for criminal recidivism-a prospective follow-up study in prisoners with substance abuse. BMC Psychiatry 12:111. doi: 10.1186/1471-244X-12-111

Hancock, M., Tapscott, J. L., and Hoaken, P. N. (2010). Role of executive dysfunction in predicting frequency and severity of violence. Aggress. Behav. 36, 338-349. doi: 10.1002/ab.20353

Hillman, C. H., Erickson, K. I., and Kramer, A. F. (2008). Be smart, exercise your heart: exercise effects on brain and cognition. Nat. Rev. Neurosci. 9, 58-65. doi: $10.1038 / \mathrm{nrn} 2298$

Hoaken, P. N., Allaby, D. B., and Earle, J. (2007). Executive cognitive functioning and the recognition of facial expressions of emotion in incarcerated violent offenders, non-violent offenders, and controls. Aggress. Behav. 33, 412-421. doi: 10.1002/ab.20194

Hofmann, W., Schmeichel, B. J., and Baddeley, A. D. (2012). Executive functions and self-regulation. Trends Cog. Sci. 16, 174-180. doi: 10.1016/j.tics.2012. 01.006

Ireland, J. L., and Culpin, V. (2006). The relationship between sleeping problems and aggression, anger, and impulsivity in a population of juvenile and young offenders. J. Adolesc. Health 38, 649-655. doi: 10.1016/j.jadohealth.2005. 05.027

Jurado, M. B., and Rosselli, M. (2007). The elusive nature of executive functions: a review of our current understanding. Neuropsychol. Rev. 17, 213-233. doi: 10.1007/s11065-007-9040-z

Kavanagh, L., Rowe, D., Hersch, J., Barnett, K. J., and Reznik, R. (2010). Neurocognitive deficits and psychiatric disorders in a NSW prison population. Int. J. Law Psychiatry 33, 20-26. doi: 10.1016/j.ijlp.2009.10.004

Kramer, A. F., Hahn, S., Cohen, N. J., Banich, M. T., McAuley, E., Harrison, C. R., et al. (1999). Ageing, fitness and neurocognitive function. Nature 400, 418-419. doi: $10.1038 / 22682$

Langan, P. A., and Levin, D. J. (2002). Recidivism of Prisoners Released in 1994. Available online at: http://www.bjs.gov/index.cfm?ty=pbdetail\& iid=1134 [Accessed July 2014].

Langevin, R., and Curnoe, S. (2011). Psychopathy, ADHD, and brain dysfunction as predictors of lifetime recidivism among sex offenders. Int. J. Offender Ther. Comp. Criminol. 55, 5-26. doi: 10.1177/0306624X09360968

Lipsey, M. W., and Cullen, F. T. (2007). The effectiveness of correctional rehabilitation: a review of systematic reviews. Annu. Rev. Law Soc. Sci. 3, 297-320. doi: 10.1146/annurev.lawsocsci.3.081806.112833

Luther, J. B., Reichert, E. S., Holloway, E. D., Roth, A. M., and Aalsma, M. C. (2011). An exploration of community reentry needs and services for prisoners: a focus on care to limit return to high-risk behavior. AIDS Patient Care STDS 25, 475-481. doi: 10.1089/apc.2010.0372

Mann, R. E., Hanson, R. K., and Thornton, D. (2010). Assessing risk for sexual recidivism: some proposals on the nature of psychologically meaningful risk factors. Sex. Abuse 22, 191-217. doi: 10.1177/10790632103 66039

McCollister, K. E., French, M. T., and Fang, H. (2010). The cost of crime to society: new crime-specific estimates for policy and program evaluation. Drug Alcohol Depend. 108, 98-109. doi: 10.1016/j.drugalcdep.2009.12.002

Melendez, R. I., Gregory, M. L., Bardo, M. T., and Kalivas, P. W. (2004). Impoverished rearing environment alters metabotropic glutamate receptor expression and function in the prefrontal cortex. Neuropsychopharmacology 29, 1980-1987. doi: 10.1038/sj.npp.1300507

Miyake, A., Friedman, N. P., Emerson, M. J., Witzki, A. H., Howerter, A., and Wager, T. D. (2000). The unity and diversity of executive functions and their contributions to complex "Frontal Lobe" tasks: a latent variable analysis. Cogn. Psychol. 41, 49-100. doi: 10.1006/cogp.1999.0734

Morgan, A. B., and Lilienfeld, S. O. (2000). A meta-analytic review of the relation between antisocial behavior and neuropsychological measures of executive function. Clin. Psychol. Rev. 20, 113-136. doi: 10.1016/S0272-7358(98) 00096-8

Munro, G. E., Dywan, J., Harris, G. T., McKee, S., Unsal, A., and Segalowitz, S. J. (2007). Response inhibition in psychopathy: the frontal N2 and P3. Neurosci. Lett. 418, 149-153. doi: 10.1016/j.neulet.2007.03.017

Norris, G., and Tate, R. L. (2000). The behavioural assessment of the dysexecutive syndrome (BADS): ecological, concurrent and construct validity. Neuropsychol. Rehabil. 10, 33-45. doi: 10.1080/096020100389282

Ogilvie, J. M., Stewart, A. L., Chan, R. C. K., and Shum, D. H. K. (2011). Neuropsychological measures of executive function and antisocial behavior: a meta-analysis*. Criminology 49, 1063-1107. doi: 10.1111/j.17459125.2011.00252.x

Petrosini, L., De Bartolo, P., Foti, F., Gelfo, F., Cutuli, D., Leggio, M. G., et al. (2009). On whether the environmental enrichment may provide cognitive and brain reserves. Brain Res. Rev. 61, 221-239. doi: 10.1016/j.brainresrev.2009. 07.002

Piquero, A. R., Jennings, W. G., Diamond, B., and Reingle, J. M. (2013). A systematic review of age, sex, ethnicity, and race as predictors of violent recidivism. Int. J. Offender Ther. Comp. Criminol. 59, 5-26. doi: 10.1177/0306624X13514733

Plugge, E. H., Foster, C. E., Yudkin, P. L., and Douglas, N. (2009). Cardiovascular disease risk factors and women prisoners in the UK: the impact of imprisonment. Health Prom. Int. 24, 334-343. doi: 10.1093/heapro/dap034

Ross, E. H., and Hoaken, P. N. S. (2010). Correctional remediation meets neuropsychological rehabilitation: how brain injury and schizophrenia research can improve offender programming. Crim. Justice Behav. 37, 656-677. doi: $10.1177 / 0093854810363104$

Ross, E. H., and Hoaken, P. N. S. (2011). Executive cognitive functioning abilities of male first time and return canadian federal inmates. Can. J. Criminol. Crim. Justice 53, 377-403. doi: 10.3138/cjccj.53.4.377

Santos Barbosa, M. F., and Coelho Monteiro, L. M. (2008). Recurrent criminal behavior and executive dysfunction. Span. J. Psychol. 11, 259-265. doi: 10.1017/S1138741600004297

Scherder, E. J., Bogen, T., Eggermont, L. H., Hamers, J. P., and Swaab, D. F. (2010). The more physical inactivity, the more agitation in dementia. Int. Psychogeriatr. 22, 1203-1208. doi: 10.1017/S1041610210001493

Scherder, E., Scherder, R., Verburgh, L., Konigs, M., Blom, M., Kramer, A. F., et al. (2013). Executive functions of sedentary elderly may benefit from walking: a systematic review and meta-analysis. Am. J. Geriatr. Psychiatry. 22, 782-791. doi: 10.1016/j.jagp.2012.12.026

Schiffer, B., and Vonlaufen, C. (2011). Executive dysfunctions in pedophilic and nonpedophilic child molesters. J. Sex. Med. 8, 1975-1984. doi: 10.1111/j.17436109.2010.02140.x

Spicer, K., Glicksman, A., and Britain, G. (2004). Adult Reconviction: Results From the 2001 Cohort. Available online at: http://collection.europarchive.org/tna/ 20080205132101/homeoffice.gov.uk/rds/pdfs04/rdsolr5904.pdf [Accessed July 2014].

Stoller, N. (2003). Space, place and movement as aspects of health care in three women's prisons. Soc. Sci. Med. 56, 2263-2275. doi: 10.1016/S02779536(02)00226-5

Vanderhoff, H., Jeglic, E. L., and Donovick, P. J. (2011). Neuropsychological assessment in prisons: ethical and practical challenges. J. Correct. Health Care 17, 51-60. doi: 10.1177/1078345810385914

Verbruggen, J., Blokland, A. A., and Van Der Geest, V. R. (2012). Effects of employment and unemployment on serious offending in a high-risk sample of men and women from ages 18 to 32 in the Netherlands. Br. J. Criminol. 52, 845-869. doi: 10.1093/bjc/azs023

Walmsley, R. (2013). World Prison Population List, 10th Edn. Available online at: http://www.prisonstudies.org/sites/prisonstudies.org/files/resources/downloads /wppl_10.pdf [Accessed July 2014].

Wartna, B. S. J., and Nijssen, L. T. J. (2006). National Studies on Recidivism: an Inventory of Large-Scale Recidivism Research in 33 European Countries. Available online at: http://english.wodc.nl/onderzoeksdatabase/1453a-internationalcomparisons-of-reconviction-rates.aspx [Accessed July 2014].

Wartna, B. S. J., Tollenaar, N., Blom, M., Verweij, D. L., Alberda, D. A., and Essers, A. A. M. (2012). Recidivebericht 2012. Available online at: http:// 
www.wodc.nl/images/factsheet-2012-6-nwtcm44-492148.pdf [Accessed July 2014].

Winterfeld, K. T., Teuchert-Noodt, G., and Dawirs, R. R. (1998). Social environment alters both ontogeny of dopamine innervation of the medial prefrontal cortex and maturation of working memory in gerbils (Meriones unguiculatus). J. Neurosci. Res. 52, 201-209.

Witte, A. V., Bagorda, F., Teuchert-Noodt, G., and Lehmann, K. (2007). Contralateral prefrontal projections in gerbils mature abnormally after early methamphetamine trauma and isolated rearing. J. Neural Transm. 114, 285-288. doi: 10.1007/s00702-006-0506-6

Woodall, J., Dixey, R., and South, J. (2013). Control and choice in english prisons: developing health-promoting prisons. Health Prom. Int. 29, 474-482. doi: 10.1093/heapro/dat019

Young, M., Waters, B., Falconer, T., and O'rourke, P. (2005). Opportunities for health promotion in the Queensland women's prison system. Aust. N. Z. J. Public Health 29, 324-327. doi: 10.1111/j.1467-842X.2005. tb00201.x
Conflict of Interest Statement: The authors declare that the research was conducted in the absence of any commercial or financial relationships that could be construed as a potential conflict of interest.

Received: 24 October 2014; accepted: 09 January 2015; published online: 30 January 2015.

Citation: Meijers J, Harte JM, Jonker FA and Meynen G (2015) Prison brain? Executive dysfunction in prisoners. Front. Psychol. 6:43. doi: 10.3389/fpsyg. 2015.00043

This article was submitted to Cognition, a section of the journal Frontiers in Psychology.

Copyright $\odot 2015$ Meijers, Harte, Jonker and Meynen. This is an open-access article distributed under the terms of the Creative Commons Attribution License (CC BY).

The use, distribution or reproduction in other forums is permitted, provided the original author(s) or licensor are credited and that the original publication in this journal is cited, in accordance with accepted academic practice. No use, distribution or reproduction is permitted which does not comply with these terms. 